\title{
Non-Invasive Determination of Left Ventricular Diastolic Compliance
}

\author{
Teruo Funumoto, M.D.* and Hugo Kesteloot, M.D.
}

\begin{abstract}
SUMmary
The log-log relationship between the instantaneous height of A wave obtained from apexcardiogram and the diameter of minor axis of left ventricle obtained by echocardiography has been calculated. The loglog slope was considered to be an indicator of ventricular stiffness. The slope was significantly higher in different subgroups of cardiac patients compared with normal subjects. This points to its possible value in the study of cardiac function.
\end{abstract}

\section{Additional Indexing Words:}

Left ventricular stiffness Fourth heart sound ST-T change on electrocardiogram Mechanocardiogram Apexcardiogram Echocardiogram Atrial contraction Log-log slope

IASTOLIC compliance of left ventricle depends both on structure and tonus of the myocardium. It is a determinant of the resistance to diastolic ventricular filling and of the atrial contribution to ventricular filling., It is also a determinant of the height of enddiastolic pressure. ${ }^{2}$ )

Until now only invasive methods could be used to determine ventricular compliance or stiffness. ${ }^{3)-51}$ Recently, however, it has been shown that the left apexcardiogram (LAC) is a mirror of left ventricular pressure especially in diastole and during isovolumic contraction. ${ }^{6)}$ Moreover, a highly significant correlation was found experimentally between the peak $\mathrm{dp} / \mathrm{dt}$ of $\mathrm{A}$ wave in the left ventricle measured with a catheter-tip micromanometer and peak dA/dt obtained from the calibrated LAC. ${ }^{7)}$ Ventricular dimensions can be calculated by a M-mode ventricular scan.

The purpose of our study is to study the relationship between diameter change and pressure change during atrial contraction in diastole, using noninvasive methods for the estimation of the necessary parameters.

From the St. Raphael University Hospital, B-3000 Leuven, Belgium.

* Present address: School of Medical Technology, University of Occupational and Environmental Health, Kitakyusyu 807, Japan.

Received for publication January 27, 1979. 


\section{Methods}

As the exact calibration of left ventricular pressure (LVP) cannot be determined from LAC, a method to obtain the relationship between LVP and left ventricular dimensions (LVD) was developed, avoiding the necessity of knowing the exact amplification of the apexcardiogram. This was done by measuring the slope of the regression equation obtained from the $\log \mathrm{A}-\log \mathrm{D}$ relationship where $\mathrm{A}$ is the amplitude of $\mathrm{A}$ wave obtained from LAC and $\mathrm{D}$ the dimension of minor axis of LV obtained from the echocardiogram during atrial contraction. The value of $\mathrm{A}$ is considered to represent its pressure counterpart in left ventricle. This log$\log$ slope is considered to be representative of the diastolic compliance of LV; the greater the value of the slope, the lower the ventricular compliance or the higher the ventricular stiffness is. This slope is the expression of the relationship between the proportional increase in amplitude of $\mathrm{A}$ wave of $\mathrm{LAC}$ and the proportional increase of ventricular diameter during atrial contraction. This slope is shown as a dimensionless value and is independent of the degree of amplification of LAC. The degree of amplification will result in changes of the intercept with $\mathrm{X}$ or $\mathrm{Y}$ axis, but not of the slope itself.

Both LAC and echocardiographic dimensions were recorded simultaneously with a phonocardiograph at paper speed of $100 \mathrm{~mm} / \mathrm{sec}$. The minor axis of LV obtained just below the level of mitral valve was used for dimensional calculations. The height of atrial $\mathrm{A}$ wave and the dimension of ventricular minor axis were measured every $10 \mathrm{msec}$ from the onset to the top of atrial systole on LAC. The 0 point (early diastolic nadir) of LAC was used as zero level for measurement of the amplitude of $A$ wave. About 6 to 10 points were obtained and used for calculations of the slope (b) of the regression equation $\mathrm{A}=\mathrm{aD}^{\mathrm{b}}$ or $\log \mathrm{A}=\log \mathrm{a}+$ $\mathrm{b} \log \mathrm{D}$ where a represents the intercept with A-D axis and $\mathrm{b}$ the slope of the regression equation, $a$ and $b$ being constants.

Total amplitude of $\mathbf{A}$ wave was measured from its upstroke to its maximum and expressed as a percentage of the total amplitude of LAC (A/T\%). The maximum increase in the magnitude of minor axis due to atrial contraction $(\Delta \mathrm{D})$ was also measured and expressed as a percentage of enddiastolic minor axis $(\% \Delta \mathrm{D})$.

The phonocardiogram was recorded in the low frequency range and the presence or absence of 4th heart sound was noted. An electrocardiogram was also recorded and patients and subjects were divided according to the presence or absence of ST deviations of $0.05 \mathrm{mV}$ or more, and of $\mathrm{T}$ wave inversion in V5 and V6. From the minor axis "ejection fraction" was calculated using the cubic formula. The ratio of systolic to diastolic posterior wall velocity (D/S) was also calculated using the method proposed by Fujino. ${ }^{8)}$

\section{Materials Studied}

Recordings were made in 10 normal control subjects aged $24 \pm 6.3$ years. Recordings were also made in 10 subjects with predominant aortic regurgitation, 4 with predominant mitral regurgitation, and they served as examples of volume overload of left ventricle. Patients with aortic stenosis $(\mathrm{N}=5)$ were considered typical cases with pressure overload of left ventricle. Moreover, recordings were 
also made in patients with congestive cardiomyopathy in whom the diagnosis was confirmed by cardiac catheterization and by a low ejection fraction.

\section{RESULTS}

The mean value of the correlation coefficients $\left(\sum r / N\right)$ between the instantaneously measured amplitude of $A$ wave and the ventricular dimension during atrial systole was 0.935 in the control subjects, 0.959 in the patients with aortic regurgitation, 0.921 in the patients with mitral regurgitation, 0.962 in patients with aortic stenosis, 0.987 in patients with cardiomyopathy and 0.955 in all cases taken together; these cases showed significant $(\mathrm{p}<$ $0.001)$ linear relationship between $\log \mathrm{A}$ and $\log \mathrm{D}$. In Table I the mean

Table I.

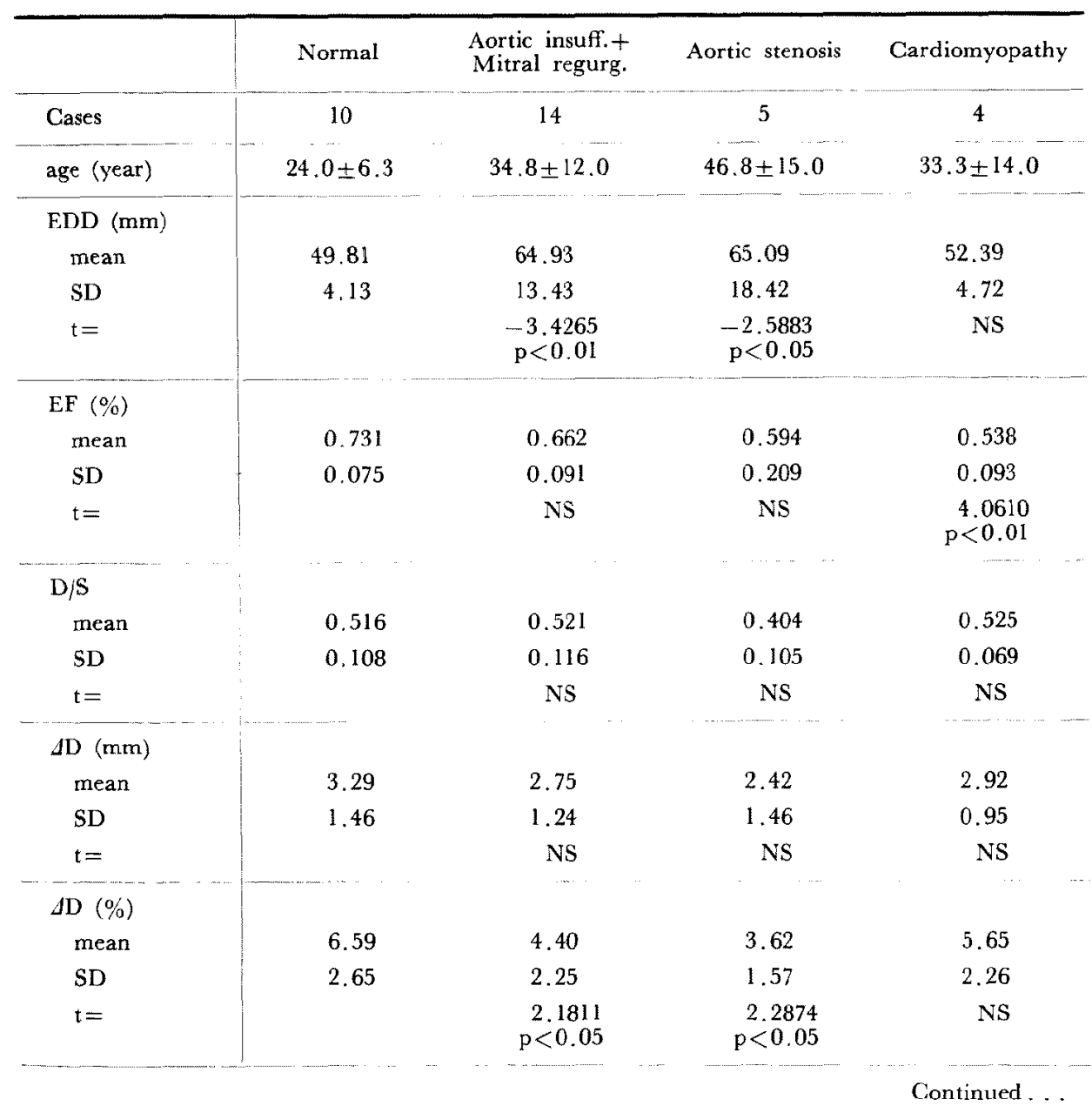


Table I. Continued

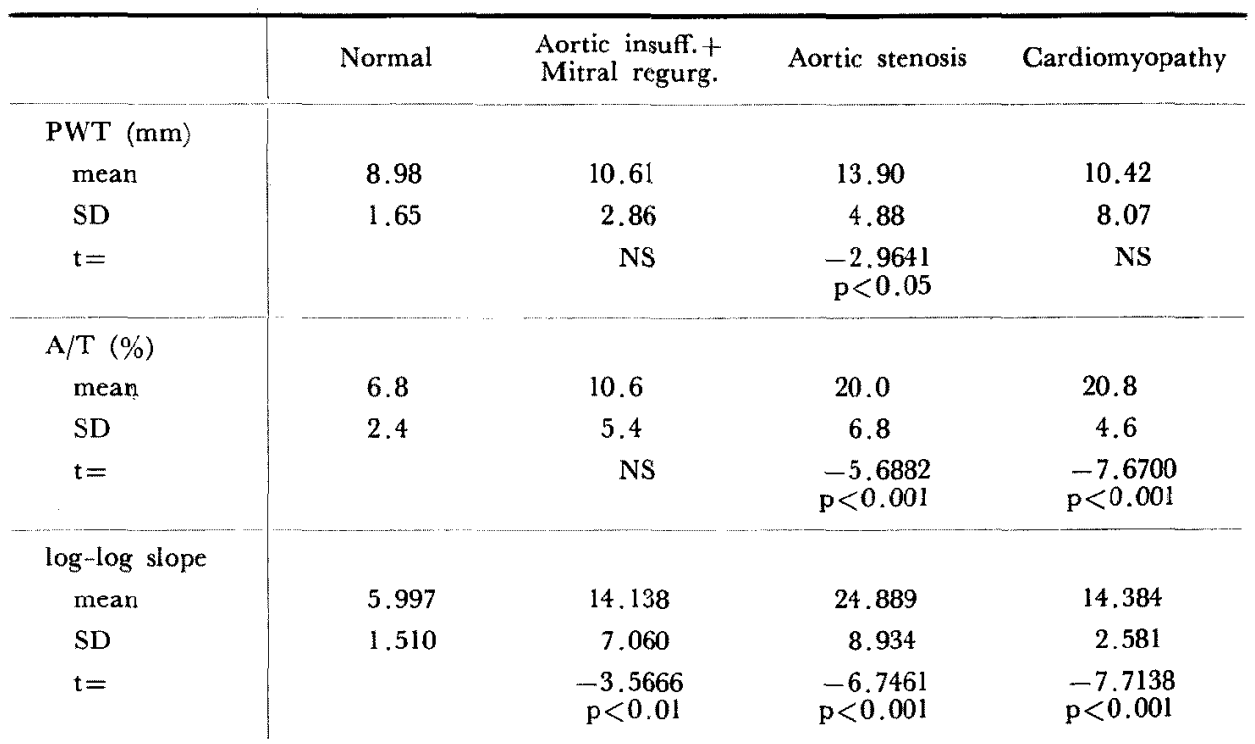

Mean values, standard deviations, and significance of the difference between the pathological groups compared with the normal group. $\mathrm{EDD}=$ enddiastolic diameter; $\mathrm{EF}=$ ejection fraction (see text); PWVD/PWVS = ratio of posterior wall velocity in systole to in diastole; $\angle D=$ diameter increase due to atrial systole; $\mathrm{PWT}=$ posterior wall thickness; $\mathrm{A} / \mathrm{T}=$ relationship of height of A-wave to total amplitude of LAC.

Table II.

\begin{tabular}{|c|c|c|c|c|}
\hline & \multicolumn{2}{|c|}{ Forth heart sound on $P C G$} & \multicolumn{2}{|c|}{ ST-T change on ECG } \\
\hline & $(-)$ & $(+)$ & $(-)$ & $(+)$ \\
\hline $\mathbf{N}$ & 16 & 17 & 15 & 18 \\
\hline $\begin{array}{l}\Delta \mathrm{D}(\%) \\
\text { mean } \\
\mathrm{DS} \\
\mathbf{t}=\end{array}$ & $\begin{array}{l}5.50 \\
2.67\end{array}$ & $\begin{array}{r}4.72 \\
2.28 \\
\text { NS }\end{array}$ & $\begin{array}{l}6.00 \\
2.58\end{array}$ & $\begin{array}{r}4.34 \\
2.16 \\
\text { NS }\end{array}$ \\
\hline $\begin{array}{c}\mathrm{A} / \mathrm{T}(\%) \\
\text { mean } \\
\mathrm{DS} \\
\mathrm{t}=\end{array}$ & $\begin{array}{l}8.73 \\
4.28\end{array}$ & $\begin{array}{c}15.41 \\
7.80 \\
-3.0196 \\
p<0.01\end{array}$ & $\begin{array}{l}8.69 \\
4.28\end{array}$ & $\begin{array}{c}15.08 \\
7.77 \\
-2.8428 \\
p<0.01\end{array}$ \\
\hline $\begin{array}{l}\log -\log \text { slope } \\
\text { mean } \\
\text { SD } \\
\mathbf{t}=\end{array}$ & $\begin{array}{l}9.23 \\
5.02\end{array}$ & $\begin{array}{c}17.18 \\
9.11 \\
-3.0775 \\
\mathrm{p}<0.01\end{array}$ & $\begin{array}{l}7.49 \\
3.22\end{array}$ & $\begin{array}{c}18.20 \\
8.20 \\
-4.7483 \\
\mathrm{p}<0.001\end{array}$ \\
\hline
\end{tabular}

Mean values, standard deviations, and significance of the difference of the groups with and without 4th heart sound, and with and without ST-T changes (see text). 
Table III.

\begin{tabular}{l|c|c|c|c|c}
\hline & $\log -\log \mathrm{b}$ & $\mathrm{A} / \mathrm{T}$ & $\mathrm{D} / \mathrm{S}$ & $\mathrm{PWT}$ & "EF" \\
\hline $\log -\log \mathrm{b}$ & 1 & $0.55 * * *$ & $\mathrm{NS}$ & $\mathrm{NS}$ & $-0.40^{*}$ \\
$\mathrm{~A} / \mathrm{T}$ & & 1 & $\mathrm{NS}$ & $0.34^{*}$ & $-0.51^{* *}$ \\
$\mathrm{D} / \mathrm{S}$ & & & 1 & NS & $0.35^{*}$ \\
$\mathrm{PWT}$ & & & & 1 & NS \\
" EF" & & & & & 1
\end{tabular}

Correlation matrix of the relationship between the measured variables. ${ }^{*} \mathrm{p}<0.05, * * \mathrm{p}<0.01$, *** $\mathrm{p}<0.001$.

values are given for the measured parameters in the 4 groups. As can be seen several significant differences were found between the normal and the patient groups. As expected the log-log slope was at its highest in aortic stenosis and this was also the case in posterior wall thickness and the $A / T$ ratio. Generally speaking posterior wall thickness, the $A / T$ ratio and the slope of $\log -\log A-D$ relationship were higher in all patient subgroups compared with normals. The $\% \Delta \mathrm{D}$ was also lower in all patient subgroups than in normal group. The slope and $A / T$ ratio were also higher in the group with a 4th heart sound compared with the group without, and were higher in the group with ST-T changes compared with the group without (Table II). The results of correlation matrix of the relationship between $\mathrm{D} / \mathrm{S}, \mathrm{PWT}, \mathrm{A} / \mathrm{T}$, and $\log -\log \mathrm{b}$ are given in Table III. A highly significant correlation was found between $\mathrm{A} / \mathrm{T}$ and $\log -\log \mathrm{b}$ but the correlation between $\mathrm{D} / \mathrm{S}$ and PWT was not significant.

\section{Discussion}

The relationships between LAC and LVP time course and magnitude, as shown in numerous animal experiments ${ }^{6)}$ and confirmed in human subjects, ${ }^{2)}$ make it possible to use LAG as an index of LVP in order to calculate LV diastolic compliance. Accurate measurements of minor axis can be obtained by echocardiography. We calculated the pressure-volume relationship of left ventricle from the $\log A-\log D$ slope, obtained during atrial systole as an indicator of passive ventricular stiffness under the assumption that pressure-dimension relationship would follow the relationship; $A=a D^{b}$, which was shown to be significantly useful in this study. Theoretically, it should be expected that a higher slope will be obtained in lower compliant ventricle due to myocardial fibrosis or left ventricular hypertrophy than in normal ventricle. This was confirmed by a finding in several subgroups of patients with aortic and mitral valve diseases and in patients with cardiomyopathy. 
These patient subgroups were not pure cases of aortic regurgitation or stenosis or of mitral regurgitation but the stated lesion was considered to be by large the predominant one. It should be noted the number of patients in all subgroups was small.

Some trials have been done for estimating the ventricular stiffness by non-invasive methods. ${ }^{5}$ ) Ventricular wall movement by atrial contraction was proposed to estimate the left ventricular function in left ventricular hypertrophy by Ambrose. ${ }^{91}$ The pressure change, however, was neglected. The $\mathrm{A} / \mathrm{T}$ ratio has also been used as a measure of left ventricular stiffness by Gibson. ${ }^{10)}$ As both $\mathrm{A}$ and $\mathrm{T}$ are influenced by different factors, an increase in both $A$ and $T$ results in normal ratio although the absolute value of $A$ may be increased. It is noteworthy, however, that $\mathrm{A} / \mathrm{T}$ is also a good discriminant between normals and pathological cases and is significantly correlated to the $\log -\log$ slope $\mathrm{b}$. One of the advantages of the $\mathrm{A} / \mathrm{T}$ ratio is that it can be obtained very easily even from an uncalibrated LAC. Since the A/T ratio only explains $30 \%$ of the $\log -\log \mathrm{b}$ slope, both indices probably contain independent information. The reason why PWT is not significantly correlated with $\log -\log b$ is probably due to the fact that hypertrophic ventricle can maintain a normal compliance under certain circumstances. The 4 th heart sound occurs when the rate of pressure increase in LV due to atrial contraction is increased. ${ }^{7}$ As expected the slope value $b$ was also significantly higher in cases where a 4 th heart sound was present. Our results suggest that the slope of the $\log$ - $\log$ relationship between the amplitude of $\mathrm{A}$ wave obtained from LAC and the ventricular dimensional changes in minor axis magnitude obtained from echocardiogram is an indicator of myocardial stiffness. The absolute value of the difference in log-log slope between normal subjects and patients is much greater than the difference in $D / S$ value as obtained by the method of Fujino. ${ }^{81}$ The method of Fujino is somewhat imprecise since it is often difficult to determine exactly the point of maximum inward movement of the posterior wall during systole.

A limitation of the method is that it can only be used in patients with sinus rhythm. Final proof of the value of the method will be obtained when a significant correlation will be shown to exist between the log-log slope obtained from the method described and the slope obtained from invasive pressure-volume measurements. ${ }^{111}$

\section{References}

1. Braunwald E, Frahm CV: Studies on Starling's law of the heart. IV. Observations on the hemodynamic functions of the left atrium in man. Circulation 24: 633, 1961

2. Dodge HT, Hay RD, Sandler H: Pressure-volume characteristic of the diastolic left ventricle 
of man with heart disease. Am Heart J 64: 503, 1962

3. Gaasch WH, Battle WE, Oboler AA, Banas JS Jr, Levine HJ: Left ventricular stress and compliance in man: With special reference to normalized ventricular function curves. Circulation 45: 746, 1972

4. Fester A, Samet P: Passive elasticity of the human left ventricle. The "parallel elastic element". Circulation 50: 609, 1974

5. Mirsky I: Assessment of passive elastic stiffness of cardiac muscle: Mechanical concepts, physiologic and clinical considerations, Direction of future research. Prog in Cardiovasc Dis 18: 277,1976

6. Willems $\mathrm{J}$, De Geest $\mathbf{H}$, Kesteloot $\mathrm{H}$ : On the value of apexcardiography for timing intracardiac events. Am J Cardiol 28: 59, 1971

7. Van de Werf F, Denef B, Aubert A, Kesteloot H: Experimental generation of diastolic heart sounds. VIII World Congress of Cardiology (abstr), 1329

8. Fujino T, Ito M, Kanaya S, Mashiba H: UCG estimation of left ventricular posterior wall motion by triangle approximation methods. A preliminary report on $\mathrm{D} / \mathrm{S}$ ratio. Proceeding of Jap J of Medical Ultrasonics 24: 117, 1973

9. Ambrose JA, Meller J, Herman MV, Teichholz LE: The ventricular A wave: a new echocardiographic index of late diastolic filling of the left ventricle. Am Heart J 96: 615, 1978

10. Gibson TC, Madry R, Grossman W, MacLaurin LP, Craige E: The A wave of the apexcardiogram and left ventricular diastolic stiffness. Circulation 49: 441, 1974

11. Laird JD: Asymptomatic slope of $\log$ pressure vs $\log$ volume as an approximate index of the diastolic elastic properties of the myocardium in man. Circulation 53: 443, 1976 